\title{
Agency and Self Expression: Fan Writing as Life Writing
}

\author{
Renu Elizabeth Abraham \\ Assistant Professor of English and Cultural Studies, Christ University, Bengaluru. ORCID: \\ oooo-0003-2043-1919. Email: renu.elizabeth@christuniversity.in
}

\begin{abstract}
Fans, fandoms and fan activities have been part of every culture from time immemorial. Homer's epics, Plato's work all could be considered in a broad sense as belonging to the larger domain of fan activity or fan 'art' as they are termed in modern day parlance. This paper examines India Forums a digital fan community based in India for audiences and fans of Indian television soaps/serials and attempts to understand how fanfiction and fan activities within this forum acts as means of self-expression and enable its fans to develop a sense of agency that is indigenous to the space in itself. This community is predominantly populated by women or 'gender anonymous' and function as a space that allow fans to construct their own voices, identities and thereby agency, which is most often restricted to that space alone. The fans though not subaltern, in the technical sense of the term, as they belong to the urban space, have access to a computer and can read, write and speak English although not fluently, are still urban middle-class women who have been spoken for and never spoken themselves; and India Forums enable these unheard voices to be heard. This reading analyses the dynamics of this agential space, the politics of this agency and argues that all fan writing within this space functions as life writing within a hypertextual metaconversational paradigm which is not necessarily reflective of traditional forms of life writing using notions of revisionist Freudian psychoanalysis and paradigms of life writing.
\end{abstract}

Keywords: Fanfiction, fandoms, life writing, self-expression, hypertextuality, Hindi TV soaps, psychoanalysis

\section{Introduction}

Identity and self-expression has been at the centre of literary expressions and representations across ages. The desire for human beings to express one's innermost thoughts and validate these expressions has been dominant even before we entered an era of "radical self-revelation" (Evans, 2005, p. 31), as indicated through our various engagements in social media platforms from Facebook, LiveJournal, Twitter, Instagram, personal blogs and vlogs and many others. In this digital era, we are configured and identified as data and these algorithmic configurations that are changing by the second are made possible by our self-inscriptions online. These self-inscriptions take multitudinous forms like online shopping, use of google and other searches, our Youtube usage and posts, use of social networking sites as mentioned above. In addition to these platforms for self-expression and validation there exist digital fandoms and fansites where individuals or fans engage in what are called fan activities.

One of the predominant fan activities available in digital spaces is fan writing. Fan writing can be grouped into a variety of expressions like FanFiction (FF), Real Person Fiction (RPF), Fan Videos (FV), Video Mixes (VM) and also general posts on the fansites. Fanfiction is the literature that fans, who are participants in a fandom create around their favoured and favourite fiction

(c) AesthetixMS 2021. This Open Access article is published under a Creative Commons Attribution Non-Commercial 4.0 International License (http://creativecommons.org/licenses/by-nc/4.o/), which permits non-commercial re-use, distribution, and reproduction in any medium, provided the original work is properly cited. For citation use the DOI. For commercial re-use, please contact editor@rupkatha.com. 
narratives and characters. This is considered a 'parasitic' form of literature as it is dependent on an original show or literature, called the canon, for its existence and survival. Video mixing belongs to the field of visual narratives and brings together alternative visual narratives constructed by fans surrounding their favourite films or television shows, mostly soap operas and fantasy fiction and real person fiction is fiction that is created around real-life celebrities.

Significant work is done to argue that fan posts and fan conversations are expressions of life writing and this paper argues that fiction, that is Fanfiction written by fans too should be considered life writing because of the circumstances that produce that writing and the politics of its dissemination and consumption. The study will examine the dynamics of the digital platform to argue that Fanfiction has to be read as an interactive continuum that includes not just the fiction in itself, but also the posts by readers of that fiction in terms of comments, suggestions, validations and criticisms. It is this continuum that constitutes the fanfictional universe as life writing.

The paper will analyse selective fan writing from the digital fandoms on India Forums to prove that Fanfiction writing and fan writing enables the fans to develop their own agency and individual identities and thus negotiate their selves within the virtual communities they inhabit and this activity is reflective of their lived experiences. India Forums hosts a digital fandom, an online fan community operating since 2003. It is, according to it's website, "a youth networking site" hosted in Mumbai, and uses rented servers based in USA. It is owned and managed by Cyberax Media Private Limited and allows registered members to

set up unique personal profiles that can be linked together through networks of friends. India-forums members can view each other's' profiles with the objective of making new friends, communicating with old friends, sharing photos and posting journals and comments etc. (India Forums, 2018).

India Forums presents itself as the \#1 entertainment discussion forum has 934029 registered members and is operational since 2003. The portal began as a discussion forum for the erstwhile Hindi television serial Jassi Jaisa Koi Nahin and today hosts discussion forums, fan clubs, chat clubs and Fanfiction on all television serials in all languages in India and also Bollywood and television industry gossip (India Forums, 2021). The community here is open and there is much traffic and interaction between members belonging to different fan communities as the members of one TV soap community might also be members of other TV soap communities. The members of the community are predominantly women or gender anonymous, as one can register using a pseudonym and gender identification while a must, can be masked as gender anonymous too. A study in this area is imperative because though much work is done on fandoms in India almost no research focuses on Fanfiction or fan writing related to Hindi TV serials which are considered 'lowbrow' among other fan communities like that of sports, cinema and celebrities.

\section{Fanfiction and fandom studies}

Fandoms and studies on fans and their fan practices have been in vogue ever since Henry Jenkins published his seminal work Textual poachers: television fans and participatory culture (1992). At a particular time when fans and their activities were associated with social stigma, Jenkins' work made positive interventions into the discourse of fans and fandoms as being individual and agential. Fandom Studies for a period of time have been dominated by euro-centric, white sensibilities (Gray et al., 2017, p. 1) and arguments centre around the necessity to become "inclusive of fan practices and affective motivations" from across marginalized cultures and practices (Gray et al., 2017, p. 1).

Jonathan Gray et al. in their Introduction on the significance of Fan Studies to the work Fandom: Identities and communities in a mediated world (2017) examine Fandom Studies as having 
crested three waves, with divergent "aims, conceptual reference points and methodological orientations" (p. 2) to rest where it is today. The first wave pioneered by Jenkins and John Fiske looks at power and representational politics to argue that fandoms and activities therein were tools used by the disempowered to subvert and appropriate "the power of the media producers and industries" (Gray et al., 2017, p. 3), through the creation of subcultural practices that enabled the evasion of control imposed on them by the power-bloc (Gray et al., 2017, p. 3). The second wave of Fan Studies considered "fans' "interpretative communities" (Gray et al., 2017, p. 3) and acts of fan consumption as embedded in existing social and cultural conditions. They were concerned with questions of gender, race, caste and age, but as continuations of wider social inequalities. It highlighted that fandom is not "an a priori space of cultural autonomy and resistance" (Gray et al., 2017, p. 5), but overlooked "individual motivations, enjoyments and pleasures of fans" (Gray et al., 2017, p. 5). The third wave became more personal in terms of its enquiry and concentrated on the "intrapersonal pleasures and motivations among fans and refocused on the relationship between fans' selves and their fan objects" (Gray et al., 2017, p. 6). The emphasis thus shifted from "the collective fandoms" in the first and second waves to the individual fan and his/her personal world in the third wave. This study also situates the study of Fanfiction and other fan writing within the third wave as fan activities that enables specific forms of self-expression and engagement. This also addresses the need to understand marginalized fan communities like that of Hindi TV serials that are located outside the larger 'canonical' fandoms like that for Star Wars, Star Trek, Harry Potter and other sports, cinematic and literary fandoms.

\section{Conceptual framework}

Sigmund Freud's work on the act of creative writing and day-dreaming in "Creative writers and daydreaming" (1908) is a seminal work in understanding the psychical machinations of creative writing and the art of sublimation. Sublimation within interpersonal psychology has interesting implications as one of the major ego defense mechanisms that enable socially unacceptable forms of engagements to bypass social stigma and censorship and fulfil the satisfaction of one's desires, or id. According to Freud in the above essay, sublimation can be understood as the transmutation or transference of libidinal energies into creative forms that help transcend social stigmatization and censorship. Freud and his notions of day-dreams/fantasises and phantasies as articulated in his various essays have been an object of study and revision ever since he posited it in 1908. It has been at the centre of the "Controversial Discussions" at the British Psychoanalytical Society in the early to mid 1940s. Sublimation as an important element of phantasy was recognised by the AustrianBritish psychoanalyst Melanie Klein and becomes an important aspect of study surrounding the processes of creativity and the work of creative imagination (R. Britton, 2013, pp.84-85). The relevance of the above work and its implications become pertinent due to its return like the ghostly spectre in Hamlet in conferences that still take place to discuss creative writing and phantasies or day-dreams-alpha (Bianchedi, 2013, p.122). Modern scholarship understands the Freudian notions of phantasying as products of repression of various kinds which emerge as sublimated in a category of writing that John Steiner (1993) calls psychic retreats which according to Britton could become pathological perversions (cited in Britton, 2013, p.104). Discussions on phantasy and creative writing are so controversial that Mauricio Abadi posited what he calls a "compromise formation" combining wish, sublimation and defense. It is interesting that across these 120 years psychoanalysts have engaged with phantasy and extended an understanding of it as extending the innermost desires repressed within the individual. The manners in which these happen are contested but that it expresses the self (repressed or otherwise) in ways that are complex and complicated is not contested. Hence, despite the "datemark" (Freud, p.424) on this Freudian notion, I use the not very contested attestations of his determinations of the creative writing self. This essay is also important 
as Ronald Britton points out that Freud distinguishes between critical and serious writing that deals with psychological truths of the human mind and writing that is escapist and is all about wishfulfillment and the essay, Creative writers and day-dreaming (1908) deals with the latter (Britton, 2013, p.102); and I argue that Fanfiction (also often abbreviated as FF) is the creative and sublimated wish-fulfilment of the 'self'. My attempt here is to read Fanfiction, as a form of creative writing using Freud's essay and the British psychoanalyst Hanna Segal's revisionist essays on Freudian concepts, Phantasy and reality (1994), and Imagination, play and art (1991) where she refocalizes Freudian notions of play, artistic conception, imagination and reality. Through these, this study argues that women's Fanfiction and fan writing as observed on India Fourms can be the effective sublimation of the writer's id into the ego.

The study will also adopt formulations on life writing to argue that if creative writing is a sublimation of the self, then it can be considered life writing given the dynamics of the continuum of narratives that make up a Fanfiction narrative within the hypertextual digital spaces. Marlene Kadar states in her essay, "Coming to terms: Life writing- From genre to critical practices" (1992), "life writing is not a fixed term, and ... it is in flux as it moves from considerations of genre to considerations of critical practice" (p.3). Kadar also points out that the issue of self and its subjectivities and also that of representation enter into considerations about what is life writing (p.3).The discussions in this study will examine Fanfiction and the fan writing surrounding the object of fandoms (the TV serials themselves) as hypertextual metaconversations that enable the personal to be expressed in multiple formulations enabling a certain agency and identity for the writers, readers/participants within India Forums.

\section{Discussion}

\section{Fanfiction as hypertextual metaconversations}

Inorder to understand the Fanfiction and fanwriting as life writing it is important to understand the operational dynamics of fanfiction within the platform India Fourms in terms of the production of the narrative, its dissemination and consumption and meaning making by the readers and participants in the forum. This will enable recognition of the nature of selfhood and self-expression as manifest in fan writing. Fandoms are manifestly transitory hypertextual public spaces that enable intensely personal ways of consumption and meaning making; and Fanfiction and fan writing that surround TV serials are just one form of such personal expressions. Fanfiction written on digital platforms like India Forums are hypertext narratives in that it allows "the presentation of information as a linked network of nodes which readers are free to navigate in a non-linear fashion. It allows for multiple authors, a blurring of the author and reader functions, extended works with diffuse boundaries, and multiple reading paths" (Keep et al., 2000).

To adopt Gerard Genette's forumlations to the analysis of Fanfiction, a Fanfiction narrative is an "architext" as it has an "entire set of general or transcendent categories---- types of discourse, modes of enunciation, literary genres---- from which emerges each singular text" (Genette, 1982, p.1). Fanfiction is transtextual in that it transcends the boundaries of a text and sets itself in relationship with other texts in a hypertextual manner. According to Genette, hypertextuality is "any relationship uniting text B (...hypertext) to an earlier text A (... hypotext), upon which it is grafted in a manner that is not that of commentary" (1982, p. 2) and Genette also points out that while a hypertext is generally considered "literary", it is not an essential that it be literary (1982, p. 5). In case of the Fanfiction produced in India Forums, the hypotext is the TV serial which is the object of the Fanfiction and the Fanfiction and writing that surround the Fanfiction is the hypertext. We observe that every fiction in its various categories like One Shot (OS), Single Story (SS), Fanfiction (FF) series and Two Shot (TS) are hypertexts that are mediated in multiple ways through 
reader comments, suggestions, criticisms and requests. The complete experience of reading a Fanfiction narrative emerges in the transtextual reading of all these responses from the readers themselves, allowing the transcendence of the fanfiction genre into a mediated and complex narrative. Often writers take suggestions and requests by readers and community members to create new work or incorporate them into the work in progress. Therefore, it is important to understand that in a digital space a Fanfiction work is not the standalone fiction itself but a continuum constituted by readers' reponses to them too which is available within the hypertextual linkages.

Fanfiction is termed as work-in-progress and is considered fragmented not just because of the nature of the writing and reading process that is hyperlinked, but also because of the interactive formation of a story through readers' interventions. These interventions though not literary in nature lend itself to the narrativization of the experience of the SS/FF/OS/TS within the fandom. Another set of transtextual interventions to Fanfiction is also in the form of likes, and dislikes that the reader can give the story. These act as signposts about the story or writing itself that helps readers pick and choose what to read. Writers actively solicit these interventions and often berate their readers for not commenting on, or liking their narratives invoking the requisite of reader intervention to validate their writing. While Kristina Busse argues that Fanfiction is intertextual, in that it alludes to the original work (canon) upon which it is built (2017, p. 45) I contend that Fanfiction on India Forums is hypertextual and the reading experience of this Fanfiction cannot be experienced without the linked responses that emerge from a reading of the text which lead to the complete aesthetic experience of the Fanfiction. In such, the writing, reading and writing cycle becomes an interdependent metaconversational continuum. India Forums is an open though tightknit community of people who come together to express their deeply personal enjoyment and engagement with specific Hindi TV soaps. This is evidenced by the fact that almost all Fanfiction is open to reading only by members of the forum. To understand this intimacy it is also interesting to note Busse quoting Matociquala, from LiveJournal, (2006, 18 May), to emphasize the contextual nature of all fanfiction.

Fanfiction is written in the expectation of being enjoyed in an open membership but tight knit community, and the writer has an expectation of being included in the enjoyment and discussion. It is the difference, in other words, between throwing a fair on the high road, and a party in a backyard. Sure, you might be able to see what's going on from the street, but you're expected not to stare. (Matociquala, 2006, as cited in Busse, 2017, p.52)

Fanfiction on online platforms, we can thus observe, does not privilege the author over the reader, but links them in a syncretic relationship. Therefore, when analysing Fanfiction in this digital community it is essential to understand it, not as a standalone hypertextual form of fiction which is serialized, but to read it as a continuous metaconversation (Busse, 2017, p.45) that grants agency to the reader to intervene in the creation of the story and its meaning making, which assists in selfexpression and identity formation.

\section{Fanfiction and fan writing as Agential}

Fan texts in the form of Fanfiction and its hypertextual continuums are one way for women to articulate their selves, their bodies and their sexualities. Fan writing and Fanfiction in the India Forums community is generally written by the urban middle-class women who have access to the Internet, who work and also either read, speak and write; or at least read and write English. Despite their urban middle-class status, access to a computer and Internet and English education, it is not wrong to argue that they are marginalized using Gayatri Chakravarty Spivak's contention in "Can the Subaltern Speak?" that this middle-class is not a category of voiceless individuals that cannot 
speak, but a group whose voice is not heard as they are always spoken for. They are spoken for on a daily basis in the soaps they watch, the advertisements that are shown amidst these soaps and even Bollywood and other new media platforms. One just needs to remember the most uncommon man, Shahrukh Khan's constant and almost fanatical reiteration of "the power of the common man" in Chennai Express (2013) to understand this point. The plight of an ordinary housewife or working woman is 'articulated' in popular culture, but these individuals themselves do not articulate themselves. But within the India Forums community they take centre-stage, but at the same time are still marginalized because the context and location of their articulation is a limited and confined space that is accessible only to like-minded people/fans who might not be able to bring about change, but can understand each other and extend constructive and positive feedback to their creative self-expressions. This marginalization is also due to the stigma associated, even today in the era of Cultural Studies and Popular Culture Studies, around Hindi soaps or Hindi serials. But within the space of the India Forums community, women/members can respond to and engage with the same characters that portray their lives in millions of homes. They write about them, scold them, commiserate with them and cry with these characters; identifying with them. They also rewrite the TV stories in terms of the lives they want to live, by remoulding the television characters according to their desires in their Fanfiction. I, therefore, argue that this group of individuals develop their own agency and identity through the act of fan writing which is essentially the urban middle-class girl or woman's way of expressing her life, desires and experiences which otherwise seem immaterial. In the fan chat club and fan forum along with likeminded others she gains a voice and identity and her experience becomes as important as any other famous person's.

\section{Fanfiction and fan writing as sublimating the self}

Sigmund Freud in his essay Creative writers and day-dreaming, traces the idea of creative writing and fantasy from childhood to adulthood. He posits that the child who indulged in 'play' often roleplaying constructions of reality to gain pleasure has graduated in adulthood to phantasizing in place of play, which invokes in him similar pleasures and also states that while play was a community and shared enterprise, phantasies are intensely personal and therefore, secret as they could be deemed "childish or unpermissible" (2010, p. 422). Freud argues,

The motive forces of phantasies are unsatisfied wishes, and every single phantasy is the fulfillment of a wish, a correlation of unsatisfying reality. These motivating wishes vary according to the sex, character and circumstances of the person who is having the phantasy; but they fall naturally into two main groups. They are either ambitious wishes, which serve to elevate the subject's personality; or they are erotic ones.(2010, p. 423)

Elizabeth Tabak de Bianchedi in her rereading of Freud's essay argues that all "phantasies are observable phenomena" in day-to-day life and that "they are imagined fictions, like screen memories,...the family romance, and so on, and are therefore conscious activities..." (1995, p.125). Segal suggests that "the relation between phantasy and reality moulds our views of the world and our personalities" (2003, p. 199).

Freud suggests that all phantasies and day-dreams have the signatures of the day dreamers' selves inscribed in them. It is this inscription of the self that induces in the dreamer a strong sense of self-preservation through concealment (2010, p. 424). Freud then links creative writing, of the kind we see in Fanfiction - adventures, romances, thrillers and dark fantasies, to day-dreams (2010, p.425). Freud also points out the processes of sublimation that enable us to enjoy a creative writer's exposition of his fantasy, but be repulsed by the exposition of a day-dreamer's fantasy. According to Segal, Freud states that unless the artist phantasy loses its ego-centric character it cannot become art (2003, p. 215) hence Fanfiction, an intensely personal form of writing that emerges from the fan's 
identification with an external object, here the Hindi TV serial, can only remain escapist literature for Freud. According to Busse, the media of Fanfiction and fan writing

clearly exhibit the layers of multiple intersecting contexts, but also illustrates how the personal and fictional sit side-by-side. ... The intimate details of one's life and fannish fantasies comment on one another in many ways, whether as escape, working through, or acting out. ...Moreover, fanfiction often tailors to our very desires, or innermost fantasies, sexual or not (2017, p. 54),

which Ellen Fremedon calls the "Id Vortex" (LiveJournal, 2004, cited in Busse, 2017, p. 54). According to Segal, "the basic function of phantasy, according to Freud is to fulfil an unfulfilled desire when it is unacceptable to consciousness, the desire and the wish fulfilling phantasy become unconscious" (2003, p.200). This part is hidden from the action of the reality principle and continues under the influence of the pleasure principle (2003, p.200) alone, operating as if it is a hidden 'self' which then emerges as a conscious wish-fulfilment, when confronted with an appropriate stimuli, in the form of, in this case, a TV serial which resonates with the mind of the Fanfiction writer. Freud and later Segal, thus leads us to the possibility of understanding Fanfiction as an extended sublimated fantasy of Fanfiction writers. Like other forms of creative writing, Fanfiction is a product of a writer's personal attachment and oftentimes identification with a particular 'canon' (here the original Hindi TV serial) and its characters. In reality this identification would possibly be considered shameful (also because unlike Harry Potter fandoms Hindi TV serial fandoms are stigmatized as not ideal) obsessions that require regulation through the reality or morality principle. But by sublimating these 'socially unacceptable identifications' and impulses from the id, that are constituted within the realm of the pleasure principle, through the creative act of imagination over phantasying, these identifications are made acceptable to the world and manifest as the working of the viewer-writer's ego (the viewer-writer in this instance the Fanfiction writer of the Hindi TV serials who watches them and then 'overwrites' them). The stimuli of these phantasies resulting in Fanfiction are dependent on the source 'canon', the TV serial itself and do not seamlessly derive from the pure unconscious id, but masquerade as though they did by fulfilling the criteria for 'original' creative work. And as Segal suggests, the supremacy of the reality or morality principle does not override the pleasure associated with the phantasy though and is expressed symbolically (2003, p.202) in the sublimated fanfiction that is produced.

Fanfiction writers write because they share a deeply proprietary relationship with the 'canon' and believe that it is part of their lives and hence they have rights to make interventions in the existing narratives inorder to make them reflect their own desires and thereby, their own selves. This is evident in the case of Fanfiction in the India Forums community. As one reader and writer in the serial Ishqbaaz's forum points out in a comment to a happy ending fan narrative of the three leads in the serial,

What a lovely story \& a befitting conclusion to Shivika story along with all the other Oberois Clap!! I so enjoyed reading about all the Oberois leading a normal domestic life without one sword after the other hanging around their necks (more so for Shivika). How I wish our show's writer had such an imagination, instead of tanking the whole show in a single shot. What sadists the makers/writers are (the emoticon for confused)." (Arudra1009, 2018)

Note the proprietary nature of the use of "our show" and the intimate shipping and renaming of the main couple into a singular portmanteau entity Shivika (Shivaay+Anika, the names of the lead characters), which is a convention in Fanfiction universes. As another reader and commentator points out reflecting the sentiments of the FanFiction writers and readers, "incredible \& wonderful story with an equally happy ending, At least here Shivika did not die a tragic death. ...". The 
fanfiction writers therefore, are at liberty to organically evolve their narrative such that there is dependence on the 'canon' or 'object' (the TV serial), but at the same time see that the symbolic manifestation (FF) is not "confused or identified" (2003, p.202), Segal puts it as the 'object' itself. The above mentioned story and comments were prefixed by another general post titled "A bad feeling" that read,

Don't you sense something weird (sic) or that bad feeling in your tummy is going to happen this week and you do not know how to stop it?

We all know that the show Ib, season 1, leap 1, redux 1 (it's up to you whatever you want to call it) is shutting down shop this week.

I think most of us will be sad or hurt of the way this happened but we have to move pass this.

We will miss all the characters that were a part of our lives in these two and a halfyears. Here's a goodbye to them all

Shivaay, Anika, Omkara, Rudra, Dadi, Tej, Shakti, Pinky; Jhanvi, Sahil, Saumya, Mala/Bela, Tia, Malika, Swetlana, Gauri, Bhavya, Khanna, Prinku (old and new).

And to the actors who will be leaving this week. Good luck and best wishes for the future. (Yvon, 2018)

From this, one can recognize the impetus behind fans writing fiction in particular ways, and how their writing is a means to represent their personal emotions and ideas, in opposition to what is happening in the daily 'reality' of their favourite shows and to their favourite characters. Thus, Fanfiction and the responses (fan writing) to the Fanfiction is a medium through which fans inscribe their selves and ideas within the closed community of India Forums, which is a platform that enables them to be heard. They can express their emotions and feelings, often in sublimated forms, through the characters and events they identify themselves with. Their identification and engagement with the soaps are so intense that they often throw tantrums in the twitter accounts of the producers and directors of the serials if the track is not going the way they want it to. This fulfils almost prophetically what Segal points out when she states, "concrete symbolism leads to misperception and false beliefs" and how desire when misinterpreted with beliefs could become irrational (2003, p.202). Despite this side, the intense personalization gets reflected in the creative Fanfiction universes they construct for and out of their favourite characters and soaps. Through these inscriptions the writers develop their own sense of self and agency by expressing themselves and constructing for themselves within their narratives. And India Forums becomes an empowering community where members encourage each other in their writing and also through comments and discussions on their writing.

The India Forums community is not just restricted to Fanfiction and comments and commentaries on Hindi TV soaps there are also general threads like that of Yvon cited above that express their personal feeling of hurt and joy at what is happening within the show's universe. There are also other posts which generally ask for advice on their love life, general help, schools and admissions and a number of day to day mundane incidents that happen in real life for them sometimes related to the serials and sometimes not. For example, the reminiscence of a young female college student who was caught in class as she was smiling to herself as she fantasized about the leads in the then popular TV soap Iss Pyaar Ko Kya Naam Doon? Another post titled "What does it take to get an Indian princess?" seeks help stating, "I Ve (sic) been wondering what I can do for an Indian lady I love. I have one am crushing on" (Marionwolisah, 2018). Another post asks 
advice on how to overcome a nasty home/-in-law scenario very reminiscent of a current popular TV serial, another one by Qusserel asks, "(f)riends, I want to buy a comfortable car for joint family trips to other regions. Our car for this has ceased to be comfortable after the birth of the second baby. What option can you advise? Where better to make a purchase?" (Need help guys, 2018). There are also instances where these communities began a series of relay calls to change regressive content in the soaps they watched resulting in changes in content. (A relay call is when the fans decide on time slots for each of them to call the Television station airing the content and get into action calling the station one after the other in a long sequence). Some of these actions have led to success, such as when they triumphed in the wrapping up of a popular 2012 show Iss Pyaar Ko Kya Naam Doon? as they refused to countenance the actor, Barun Sobti who played Arnav Singh Raizada the male lead in the serial, being replaced. In other instances the lead actors were reinstated following fan protests too. The fan communities are able to bring about changes through their collective action because they have invested their selves into these soaps and made them a part of their lives. This kind of intense "projective identification" (Segal, 2003, p.206) can also be considered pathological as the "self here acts because s/he feels "tied and pulled by the object" into which a part of their selves are invested ((Segal, 2003, p.206), depending on the perspective of the study. In this instance, I selectively look at these instances as engagements that manifest their selves through collective action as they are based on "recognition of realities", which then forms the basis for rational action (Segal, 2003, p.207).

There are the multiple ways in which members of the India Forums community voice their opinions, make themselves heard and carve out an identity for themselves even as it is as fans of a serial. As belonging to the India Forums community they get identified and feted according to the ladder groups they belong to. These identities are dependent solely on their contribution to the community (see Fig. 1).

\begin{tabular}{|c|c|c|}
\hline S1. No & Ladder Group & No. of Posts \\
\hline 1 & Newbie & 0-49 \\
\hline 2 & Groupbie & $50-199$ \\
\hline 3 & Senior Member & $\mathbf{2 0 0 - 9 9 9}$ \\
\hline 4 & Goldie & $1000-2499$ \\
\hline 5 & Dazzler & $2500-4999$ \\
\hline 6 & IF-Rockerz & $5000-9999$ \\
\hline 7 & IF-Sizzlerz & $10000-24999$ \\
\hline 8 & IF-Stunnerz & $25000-49999$ \\
\hline 9 & IF-Addictz & $5000-99999$ \\
\hline 10 & IF-Achieverz & $10000+$ \\
\hline
\end{tabular}

Fig. 1. (Vijay, 2012) Retrieved from https://www.indiaforums.com/forum/topic/3014856 
This allows the members of India Forums a certain agency which is solely contribution-based, and as you progress up the ladder group you also get a say in admin decisions which further enables the community member. In this manner, parity is established and each member can progress through their contributions. Fan writing provides agency to ordinary women who would otherwise not have a voice that could be heard in public, as most often their language prowess and thematic engagements might not meet professional publishing standards or also because the serialised interactive way of developing a story grants them more space and freedom. It enables them to express themselves and be heard and heeded, as, according to Thomas Smith, "agency,..., is the ability of individuals to negotiate societal systems to make meanings for themselves that allow them to act, in however circumscribed a manner, in the world" (2001, as cited in Buss, 2005, p. 9).

\section{Fanfiction as life writing}

Autobiographical practices "effectively reveal agency or the desire for agency because they show how meanings are created for people, how people create meanings for themselves, and how people engage in the world around them" (Smith, 2001, as cited in Buss, p. 9). Fan writing, (both Fanfiction and all fan posts, fan art, protest calls) does precisely this for a group or 'community' of people. Taking specific examples from fandoms like India Forums we see that these platforms become spaces for people who enjoy similar tastes to come together and form social and cultural bonds, engage in processes of meaning making that provide them meaning in life even beyond the 'canon' they engage with. This can be seen in numerous instances where fans share their joys and sorrows, like births, illness, deaths, exams, results and such with each other on the sites. Over constant questions and retellings and answers a narrative of their life emerges and more personal and meaningful interactions are brought about. Also in a different way Johnnie Gratton's view on autobiographies as life writing can be applied to Fanfiction. He states,

(T)he non-existence of my life story also makes it necessary for me to produce 'fiction' in a good sense: fiction as making and not just making up; fiction as the corollary of imagination, fantasy and desire; fiction as the supplement of memory (a supplement probably always already in memory). In short, fiction is coextensive with the idea of a performative dimension. It affirms the increasingly highlighted 'act-value' of autobiographical writing at the expense of its traditionally supposed 'truth-value'." (Gratton, 1997, as cited in Gudmundsdóttir, 2003, p. 4)

The traditional understanding of life writing as auto/biographical is limiting as it emphasizes objective truths and narrative linearity disprivileging narrative fragments and nonlinear narrations and was dominantly patriarchal (Kadar, 1992, p.3). A reformulation of life writing included women's writing in the form of diaries, letters and such but still privileged the idea of nonfiction which was deemed patriarchal with many women writers and critics like Nicole Brossard who holds that there is no fiction (qtd in Kadar, 1992, p.5). Postmodernist life writing epistemological practices problematize the idea of fiction and non-fiction, and prefer the radicalizing of genres over rigid classifications particularly when it comes to women's writing as women's objective selves are a priori determined by the larger patriarchy they are embedded within. This necessitates a relook at their 'objective' expressions and Kadar and other critics make attempts to radicalize the genre to include within life writing the fictional frame as well; particularly in the case of women's experimental writing (Kadar, 1992, p. 6) as is the case of almost all Fanfiction in India Forums. An important feature of writing within the Fanfiction genre in India Forums is the open sexual content within them, which is absent within the silver screen portrayals of their 
character's lives. For example, here are a few excerpts from Fanfiction from the serial Iss pyaar ko kya naam doon?

'Don't worry, just relax, lean a little forward, feel me when I'm moving, and try to stay in front of me', as he picked her upto his chest, she quaked...She could feel his sweat through the beats of his heart. His weight shifted and so did hers.... (Mysticaldivine, 2015)

...Both claim each other intimately by using Touch and Heat of their mingling bodies. (Mysticaldivine, 2015)

'Learnt from the best, you!' Khushi whispered as she reached for him and kissed both of his cheeks one by one. 'There you go.' She smiled as she heard him sigh. 'And I guess now I owe you?' asked Arnav, running a finger behind her right earlobe. (the_rain, 2011)

As evidenced Fanfiction is a result of an individual's investment personally and collectively in the project that $\mathrm{s} /$ he is a part of. For most writers who belong to fan communities, every line they write, whether it is a work of fiction or a response or a comment on the 'canonical' text, is because they have made that TV soap a part of their lives and they believe that they have a personal say in the narrative, a voice that requires recognition and affirmation. In the India Forums community, bound by rules and a community of writers and readers who are generally sensitive, which protect them against negativity and problems of self-esteem, the India Forums writer (the fan) can be who they want to be at all times within that digital cocoon which provides them with a voice and agency of their own. Reminiscent of Virginia Woolf's dictum for women, this community, for the average fan writers and participants, functions as a 'room of their own'.

The context of the conversation between writer and reader also determine the creation of the hypertextual Fanfiction. The reader responds to the writing with their own experiences, comments and engagements in real time and real life. This metaconversation (Busse, 2017, p. 45) between reader and writer which translates into interventions in the writer's writing also make this experience trasnstextual as much as it is non-fiction. By reading Fanfiction as a hypertextual metaconversation between reader and writer it becomes as much life writing and a writing of life itself. This is what radicalizes the non-linear and experimental writing of Fanfiction as something beyond tautology. What is also interesting about Fanfiction that is hypertextual is that the 'life' inscribed in these writings is not just the author's life but more dominantly the readers'. Fanfiction as a genre of writing attempts to bring the reader and author together in a seamless relationship of production and consumption where their roles are not restricted to one or the other and transcends to include both.

Life writing comprises texts that are written by an author who does not continuously write about someone else, and who also does not pretend to be absent from the [black, brown, or white] text himself/herself. Life writing is a way of seeing, to use John Berger's famous phrase; it anticipates the reader's determination on the text, the reader's colour, class, and gender, and pleasure in an imperfect and always evolving hermeneutic... (Kadar, 1992, p.10)

Fan writing is unabashedly personal and intense and responses to the fiction themselves are passionate as they reflect the almost fetishized devotion the fan club members hold for their objects of desire, the specific TV soaps and their characters. And a writing that emerges from such deeply fetishistic roots cannot help being an expression of their own selves and lives, either as a mode of escape or a heightening of their personal experiences. The author/writer of Fanfiction is aware, because of their engagements within India Forums, that all of them share the same ideologies and motivations and as such they do not have to restrain themselves from being what they are or want to be within the community. Rules on the forum forbid nasty comments and negative comments, 
with moderators deleting such posts and warning members. Anonymity to real life identities can be masked by using pseudonyms and handles ensuring a 'carnivalesque' (Mikhail Bakhtin) manner of self-expression and gratification. Thus, the fandom itself becomes an empowering space for women and others for self-expression and validation by creating for themselves a safe space and agency.

\section{Conclusion}

One can observe that fan writing with all its dimensions is a life-performance of the fan. And these practices not only invoke a sense of agency in the participants but in fact construct agency/ies for them. Fanfiction and other fan writing can also be writings of the self in various degrees which enables the writer and the reader to understand themselves and negotiate with the world around them. Though this study focuses on only the idea of life writing in general it will be rewarding to understand this area also in terms of specific engagements with its gendered dimensions. Focussed study is not available on fandoms that surround television serials in Hindi or other regional languages, and when they rarely do, focus is on the celebrification of stars/actors. Hence, a critical approach towards regional TV soap fandoms will through light on the politics and possibilities of gender, self and agency that operate on these forums.

\section{References}

Arudra10o9. (2018, December 14). In Smilesruz. (2018, December 13). Ishqbaaaz- A happy ending. India Forums. https://www.india-forums.com/forum_posts.asp?TID=5055164

Busse, K. (2017). Intimate intertextuality and performative fragments in media fanfiction. In J Gray, C Sandvoss, \& C. L. Harrington (Eds.), Fandom: Identities and communities in a mediated world (2nd ed., pp. 45-59). New York University Press.

Buss, H. M. (2005). Katie.com: my story: Memoir writing, the Internet and embodied discursive agency. In M. Kadar, L. Warley, \& S. Egan (Eds.), Tracing the autobiographical (pp. 9-23). Wilfrid Laurier University Press.

Britton, R. Reality and unreality in phantasy and fiction. (2013). In E S Person, P Fonagy, \& S A Figueira (Eds.), On Freud's 'creative writers and day-dreaming' (1995), (pp. 82-106). Karnac Books.

De Bianchedi, Elizabeth Tabak. (2013) Creative writers and dream-work-alpha. In E S Person, P Fonagy, \& S A Figueira (Eds.), On Freud's 'creative writers and day-dreaming' (1995), (pp. 122-132). Karnac Books.

Evans, M. (2005). Auto/biography as a research method. In Gabriele Griffin (Ed.), Research methods for English studies (pp. 31-46). Rawat Publications.

Freud, S. (2010). Creative writers and day-dreaming. In Vincent B. Leitch (Ed.), Norton anthology of literary criticism and theory (pp. 420-430). W Norton and Company.

Genette, G. (1982). Palimpsests: Literature in the second degree. University of Nebraska Press.

Gray, J. et al. (2017). Introduction: Why still study fans?. In Fandom: Identities and communities in a mediated world (2nd ed.) (pp. 1-26). New York University Press.

Gudmundsdóttir, G. (2003). Introduction: Autobiography and fiction. In Borderlines: Autobiography and fiction in postmodern life writing (pp. 1-10). Rodopi B.V.

India Forums. (2021, January 20). About us. http://www.india-forums.com/about_us.asp 
India Forums. "Privacy policy”. (2018, December 2020). Privacy policy. https://www.indiaforums.com/privacypolicy.asp

Kadar, M. (1992). Coming to terms: Life writing - From genre to critical practices. In Marlene Kadar (Ed.), Essays on life writing: From genre to critical practice (pp. 3-16). University of Toronto Press.

Keep, C. et al. (2000). Hypertext. In The electronic labyrinth.

http://www2.iath.virginia.edu/elab/hfloo37.html

Marionwolisah. (2018, October 13). What does it take to get an Indian princess?. India Forums. https://www.india-forums.com/forum_posts.asp?TID=5036628

Mysticaldivine. (2015, January 23). A tribute to Teri Meri celebration $\sim$ passionate dance. https://www.indiaforums.com/forum/topic/4291304\#118686489

Quesserel. (2018, November 15). Need help guys. India Forums. https://www.indiaforums.com/forum_posts.asp?TID=5046495

Segal, Hanna. (1991). Imgination, play and art. In Riccardo Steiner (Ed.), Unconscious phantasy (2003), (pp. 211-221). Karnac Books.

---. (1994). Phantasy and reality. In Riccardo Steiner (Ed.), Unconscious phantasy (2003), (pp. 199-209). Karnac Books.

The_rain. (2011, August, 22). Arhi ff: His gardening, her jalebi. Part 1, chapter 2. https://www.indiaforums.com/forum/topic/1761815?pn=7

Vijay. (2012, June 12). New ladder groups update. India Forums. https://www.indiaforums.com/forum/topic/3014856

Yvon. (2018, December 11). A bad feeling. India Forums. https://www.indiaforums.com/forum_posts.asp?TID=5054715.

\section{Author's Bionote}

Renu Elizabeth Abraham is an Assistant Professor of English with the Department of English and Cultural Studies, CHRIST (Deemed to be University), Bannerghatta Road Campus, Bengaluru, India. Her academic interests lie in Children's Literatures in India, Fandom Studies and Popular Culture Studies in India and she has recently published a monograph on Children's magazines in English in India. 